\title{
UTERINE ARTERY DOPPLER INDICES AS PREDICTIVE MEASURES FOR THE PRE-ECLAMPSIA AND INTRAUTERINE GROWTH RESTRICTION *RASHID MN ${ }^{1}$, KARI $M^{2}$, RASHID $\mathbf{R}^{1}$, RANA MA ${ }^{3}$, AMJAD A $^{4}$, HAFEEZ MM ${ }^{5}$ \\ ${ }^{I}$ University Institute of Radiological Sciences and Medical Imaging Technology, The University of Lahore, Lahore, Pakistan \\ ${ }^{2}$ Fatima Jinnah Medical University, Lahore, Pakistan \\ ${ }^{3}$ Intensive Care Unit, Bahria International Hospital, Lahore, Pakistan \\ ${ }^{4}$ PSRD College of Rehabilitation Sciences, Sialkot, Pakistan \\ ${ }^{5}$ Institute of Molecular Biology and Biotechnology, The University of Lahore, Lahore, Pakistan \\ Corresponding author: drnabeelrasheed@gmail.com
}

(Received, $17^{\text {th }}$ May 2020, Revised $31^{\text {th }}$ August 2020, Published $8^{\text {th }}$ September 2020)

\begin{abstract}
Preeclampsia and Intrauterine growth restriction (IUGR) remains as the important causes for the neonatal and maternal complications leading to even death in some cases. Uterine artery Doppler USG can be done transvaginally or trans abdominal and performed in the 1st or 2nd trimester of the pregnancy to detect these complications Doppler waveform suggested the high vascular resistance to blood flow. In our present study, we conclude uterine artery Doppler indices as prognostic procedure for the preeclampsia and intrauterine growth restriction. A cross-sectional survey design with convenient sampling technique was used. Mixture of standardized and self-modified structured questionnaire was undertaken to determine the indices of pre eclampsia and IUGR by uterine artery. The data was collected from Bahria International Hospital, Lahore during the period of 9 months. This study was included 162 pregnant females with identification of the main uterine artery on a longitudinal scan lateral to the uterus. Initial diastolic notch of right and left side of the uterine artery waveforms was recorded. At every antenatal checkup, urine was tested for protein and blood pressure readings were taken to identify preeclampsia. Further analysis was done dividing patients as normotensive and those patients developing hypertension after 30 weeks of gestation. After delivery neonates observed for IUGR by head circumference and body weight. The study was concluded that from the total sample size of 162 pregnant females who undergoes uterine artery Doppler, $34 \%$ females shows diastolic notch and almost all of these later diagnosed with preeclampsia and $19.8 \%$ deliver babies with IUGR. So, based on the study, we have concluded that uterine artery Doppler is helpful to provide diagnosis of preeclampsia and IUGR in early pregnancy.
\end{abstract}

Keywords: Pre-eclampsia, Intrauterine growth restriction, Uterine artery Doppler ultrasonography, hypertension, pregnancy

\section{Introduction}

Pregnancy related pre eclampsia is the condition with no certain etiology and involves different physiological processes. The pathological reasons of pre eclampsia is still under investigations. Conversely, it is supposed to arise in two stages. Stage one incorporate the confined placental low oxygen supply and waning of fetal trophoblastic invasion of the decidua. Another stage which is second stage, in which release of different blood related factors, like angiogenic and pro inflammatory manisfestation occurs in blood of pregnant female (Albu et al., 2014). Pre eclampsia is commonly categorized by raised blood pressure and protein urine, with the medical demonstration generally happening through the mid of second trimester or third trimester of pregnancy and relapsing after delivery.
This comprises of two chief categories: initialcommencement pre eclampsia(arising before thirty four weeks of gestation) and late-commencement of pre eclampsia (arising afterward thirty four weeks of gestation). Even though the donating structures of initial- and late-onset pre eclampsia might overlay, early-onset pre eclampsia is related through improved odds of difficulties, predominantly ,baby born before forty weeks, growth of baby restraint and maternal indisposition and death equated to late onset pre eclampsia (Litwinska et al., 20017). The definition of intrauterine growth restriction is a fetur growth not as much of the normal growth prospective of a definite infant because of hereditary or conservational reasons. The terms IUGR and Small for Gestational Age (SGA) are frequently cast-off to label the similar problem,

[Citation: Rashid M.N., Kari, M., Rashid, R., Rana, M.A., Amjad, A., Hafeez M.M. (2020). Uterine artery doppler indices as predictive measures for the pre-eclampsia and intrauterine growth restriction. Biol. Clin. Sci. Res. J., 2020: 23 doi: https://doi.org/10.54112/bcsrj.v2020i1.23] 
even though here are refined differences among the two. SGA is identified as birth weight less than $10 \%$ intended for that specific gestational age, parity and gender the population standards on the growth chart. IUGR is a clinical description and practical to new borns with clinical suggestions of malnourishment (Cnossen et al., 2008; Malik et al., 2020).

Hypothetically, a uncontrolled upsurge in the vascular resistance of plecenta must stay measureable from the uterine arteries doppler ultrasonography and also measuring PI values, it might be compromise the prospective to identify the different abnormal conditions related to pregnancy like preeclampsia and IUGR (Turk et al., 2019). Operative showing intended for preeclampsia may be accomplished from amount of the pulsatility index of uterine artery in doppler ultrasound eleven to thirteen weeks' gestation, cast-off in grouping of motherly history, hypertension, Identification of plasma protein $\mathrm{A}$ in and restrictive growth of plecenta. Aimed at, a false-positive degree of $5 \%$, that one has remained measured from the novel shared technique of showing may expect around $90 \%$ of medical cases of PE demanding to give birth previously 34 weeks and $45 \%$ of cases of late-onset pre-eclampsia or uterine artery PI dimension, the pregnancy should be among $11+0$ and $13+6$ weeks Transabdominal ultrasound must be cast-off to attain a midsagittal section of the uterus and cervical canal. The internal cervical OS might be recognized and the transducer skewed gradually from side to side in each paracervical area, by means of color flow mapping, to recognize the uterine arteries as aliasing vessels flowing laterally the side of the cervix and uterus (MacDonald and McCarthy, 2015). Technique used to achieve waveform flow velocity which is coming form the ascending division of the uterine artery is pulsed wave doppler. After successive achieving mean from three values or three similar waveforms are gotten, the pulsatality index might be stately and calculated and the overall pulsatility index of the left and right arteries calculated. or uterine artery pulse index measurement, the gestational age necessity be between $11+0$ and 13 +6 weeks. Transabdominal ultrasound would be used to acquire a midsagittal section of the uterus and cervical canal. The internal cervical OS would be recognized and the transducer tilted softly from side to side in each paracervical area, by means of color flow mapping, to recognize the uterine arteries as aliasing vessels flowing lengthways the side of the cervix and uterus (Ciobanu et al., 2019). Doppler ultrasound of pulsed wavefroms might be binding-off for achieving the velocity of waveforms from the branch which is coming uterine artery and giving ascending branches at the point closest to the internal os. When three similar consecutive waveforms were gotten, the PI which should be dignified and the mean PI of the left and right arteries were calculated as 4, 7. In this study, we determine uterine artery doppler indices as predictive measures for the preeclampsia and intrauterine growth restriction (Turk et al., 2019; Malik et al., 2018; Pialis et al., 2007). In this study, we determine uterine artery doppler indices as predictive measures for the preeclampsia and intrauterine growth restriction.

\section{Objective}

To determine uterine artery doppler indices as predictive measures for the preeclampsia and intrauterine growth restriction.

\section{Methodology}

A longitudinal study design was used. Data was collected from the pregnant females. Non probability purposive sampling technique was used in this study. Sample size was 162 with $5 \%$ precision level. In inclusion Criteria pregnant females of aged between 18 to 40 years and having 18 to 30 weeks of gestation were included. Those pregnant females who had diabetes or hypertension before pregnancy or females who had fetal anomaly were excluded in our study. Uterine artery ultrasound were done by color Doppler power vision with $4 \mathrm{MHz}$ convex array transduce and early diastolic notches from both sides were recorded and after that on follow up round blood pressure and protein urine sample were collected to see the presence of proteinuria to detect preeclampsia. Data was collected from 162 participants through a self made questionnaire and it was purposive approach for collecting samples. Data was entered in SPSS version 22 and graphs were formulated afterwards.

\section{Results}

Table 1. Descriptive statistics of Age

\begin{tabular}{lll}
\hline Age & Frequency & Percent \\
\hline 18 to 29 years of age & 69 & 42.6 \\
29 to 40 years of age & 93 & 57.4 \\
Total & 162 & 100 \\
\hline
\end{tabular}

The table 1 shows that the $42.6 \%$ females are in age group of 18 to 29 years and $57.4 \%$ females are in age group of 29 to 40 years.

Table 2. Descriptive statistics of Notch

\begin{tabular}{lll}
\hline Notch & Frequency & Percent \\
\hline Right notch & 19 & 11.7 \\
Left notch & 15 & 9.3 \\
Bilateral notch & 21 & 13.0 \\
No notch seen & 107 & 66.0 \\
Total & 162 & 100 \\
\hline
\end{tabular}

The table 2 analysis shows that the $11.7 \%$ USG shows right notch, 9.3 shows left notch and $13 \%$ USG of pregnant females shows bilateral notch. Remaining 66\% shows no notch during USG of gestation period between 18 to 30 weeks.

Table 3. Descriptive statistics of Gestational Age

Gestation weeks $\quad$ Frequency Percent

[Citation: Rashid M.N., Kari, M., Rashid, R., Rana, M.A., Amjad, A., Hafeez M.M. (2020). Uterine artery doppler indices as predictive measures for the pre-eclampsia and intrauterine growth restriction. Biol. Clin. Sci. Res. J., 2020: 23 doi: https://doi.org/10.54112/bcsrj.v2020i1.23] 


\begin{tabular}{lll}
\hline $\mathbf{1 8}$ to 24 weeks & 93 & 57.4 \\
$\mathbf{2 4}$ to 30 weeks & 69 & 42.6 \\
Total & 162 & 100 \\
\hline
\end{tabular}

The table 3 analysis shows that the USG performed in $57.4 \%$ females having gestation period between 18 to 24 weeks and remaining $42.6 \%$ had 24 to 30 weeks of gestation.

Table 4. Descriptive statistics of Proteinuria after 30 weeks of Pregnancy

\begin{tabular}{lll}
\hline Proteinuria & Frequency & Percent \\
\hline Present & 54 & 33.3 \\
Not Present & 108 & 66.7 \\
Total & 162 & 100 \\
\hline The table 4 & analysis shows & that $33.3 \%$
\end{tabular}

The table 4 analysis shows that $33.3 \%$ had proteinuria after 30 weeks.

Table 5. Descriptive statistics of BP

\begin{tabular}{lll}
\hline BP after 30 weeks & Frequency & Percent \\
\hline More than 140/90 & 55 & 34 \\
Less than 140/90 & 107 & 66.0 \\
Total & 162 & 100 \\
\hline
\end{tabular}

The table 5 analysis shows that $34 \%$ females having high BP at different times and remaining $66 \%$ shows normal BP reading of both systolic and diastolic. This variable is related to diagnoses of preeclampsia.

Table 6. Descriptive statistics of Preeclampsia

\begin{tabular}{lll}
\hline Pre Eclampsia & Frequency & Percent \\
\hline Yes & 53 & 32.7 \\
No & 109 & 67.3 \\
Total & 162 & 100
\end{tabular}

The table 6 analysis shows $32.7 \%$ females had pre eclmapsia after 30 weeks of gestation.

Table 7. Descriptive statistics of IUGR

\begin{tabular}{lll}
\hline IUGR & Frequency & Percent \\
\hline Yes & 32 & 19.8 \\
No & 130 & 80.2 \\
Total & 162 & 100 \\
\hline
\end{tabular}

Results of the following study demonstrate the accuracy of the assessment of Notch and Pulsatility Index among the pregnant females reporting for Intrauterine growth restriction (IUGR) and preeclampsia. Findings of the study suggested both parameters to be quite sensitive in stating if the female is undergoing IUGR or not (Table 7). After finding the area under curve (AUC) among the parameters the results show values of 0.935 and 0.858 (Figure 1) for Notch and Pulsatility index respectively. Moreover, contingency table was drawn among the Notch-IUGR and Pulsatility index-IUGR to state negative predictive variable (NPV), positive predictive variable (PPV), Sensitivity and Specificity of Notch and Pulsatility index for the occurrence of IUGR. Negative predictive variable and positive predictive variable (NPV and PPV) of the Notch and pulsatility index expresses the higher accuracy of the Notch over the pulsatility index in determining the intrauterine growth restriction (IUGR) (Tables 8 and 9). The PPV and NPV (Table 10) for both variables were recorded as $(36 \%, 99 \%)$ and $(30 \%, 99 \%)$ respectively. Similarly, both the parameters express to be equally sensitive in the determination of IUGR with sensitivity of $95 \%$ whereas, as far as specificity is concerned pulsatility index expressed $66 \%$ and Notch was $75 \%$ (Table 11) specific in the determination of the said condition. Thus, it can be said that Notch determination is quite more specific and sensitive for the determination of intrauterine growth restriction (IUGR).

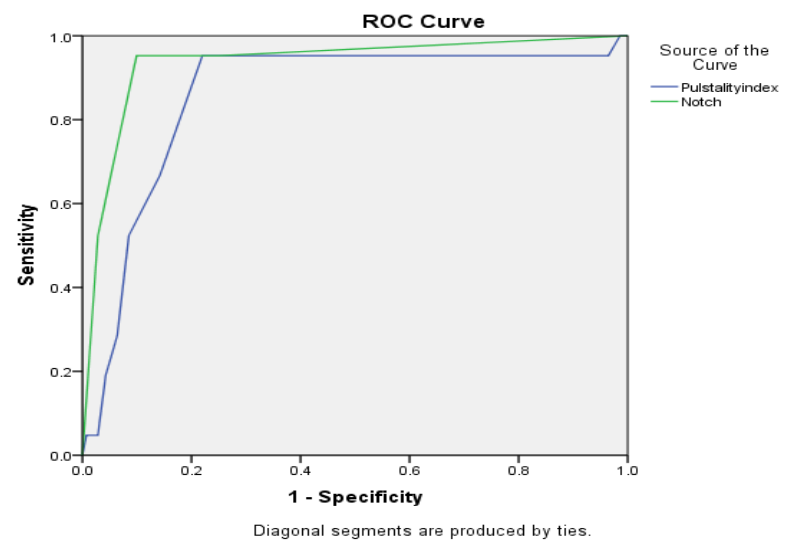

Figure 1. The are under curve for sensitivity and specificity Table 8. Contingency table of Notch with IUGR

\begin{tabular}{|c|c|c|c|c|}
\hline & & IUGR & & \\
\hline & & YES & NO & Total \\
\hline & YES & 20 & 35 & 55 \\
\hline & & True Positive & False Positive & \\
\hline 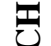 & NO & 1 & 106 & 107 \\
\hline 동 & & False Negative & True Negative & \\
\hline Z & Total & 21 & 141 & 162 \\
\hline
\end{tabular}

Specificity $=d / d+b=106 / 106+35=0.75$

Sensitivity $=a / a+c=20 / 20+1=0.952$

Table 9: Contingency table of PI with IUGR

\begin{tabular}{cllll}
\hline & & & \\
\cline { 3 - 4 } & YUGR & NO & Total \\
\hline \multirow{2}{*}{ NO } & 20 & True Positive & False Positive & \\
& 1 & 94 & 97 \\
& False Negative & True Negative & \\
a & Total & $\mathbf{2 1}$ & $\mathbf{1 4 1}$ & $\mathbf{1 6 2}$ \\
\hline
\end{tabular}

$\mathrm{PPV}=\mathrm{a} / \mathrm{a}+\mathrm{b}=20 / 20+47=0.298$

$\mathrm{NPV}=\mathrm{d} / \mathrm{c}+\mathrm{d}=94 / 94+1=0.989$

Specificity $=d / d+b=94 / 94+47=0.666$

Sensitivity $=a / a+c=20 / 20+1=0.952$

Table 10. Contingency Table showing PPV and NPV of Notch vs PI

[Citation: Rashid M.N., Kari, M., Rashid, R., Rana, M.A., Amjad, A., Hafeez M.M. (2020). Uterine artery doppler indices as predictive measures for the pre-eclampsia and intrauterine growth restriction. Biol. Clin. Sci. Res. J., 2020: 23 doi: https://doi.org/10.54112/bcsrj.v2020i1.23] 


\begin{tabular}{|c|c|c|}
\hline \multirow{3}{*}{$\begin{array}{l}\text { NOTCH } \\
\text { PI }\end{array}$} & PPV & NPV \\
\hline & $36 \%$ & $99 \%$ \\
\hline & $30 \%$ & $99 \%$ \\
\hline \multicolumn{3}{|c|}{$\begin{array}{l}\text { Table 11: Estimation of specificity and } \\
\text { among ratios (Notch and PI) }\end{array}$} \\
\hline & Sensitivity & Specificity \\
\hline NOTCH & $95 \%$ & $75 \%$ \\
\hline PI & $95 \%$ & $66 \%$ \\
\hline
\end{tabular}

\section{Discussion}

A condition characterized by increases blood pressure during the pregnancy and followed by organ perfusion with extreme vascular spasm is known as preeclampsia (Ciobanu et al., 2019; Pialis et al., 2007). Preeclampsia causes many complications and death of pregnant mothers in developing areas of the world and Organization of world health WHO estimated that more than ten lacs pregnant women die from this condition (Damodaram et al., 2010). However, Incidence of preeclampsia influenced by race ethinicity and hereditary and genetic changings and most of the young females and nulliparous women suffering from this condition (Yamaleyeva et al., 2017). There is a non invasive technique which is used for detecting this condition by uterus-plecental blood flow, called Uterine artery Doppler ultrasonography (Finn-Sell et al., 2018). Most of the researches shows that notch shows in ultrasonography in second trimester was effective in diagnosis that condition and our study also shows that this is somehow this is true because our results also predicts that, preeclampsia happened in those women in which notch was seen (Harman and Baschat, 2003). For the evaluation of the prognostic uterine artery values of doppler usage in the prevalence of $\mathrm{PE}$ and intrauterine growth discussing to the obstetric department of Bahria Hospital. A prospective cohort study, Hundred eight pregnant females with mean age of twenty eight years goes for uterine artery Doppler ultrasound at second trimester of pregnancy. A research conducted by Turk et al., (2019) who have selected hundred pregnant females and their uterine artery doppler ultrasound was performed, average age of females were 23.2 from 11 to 14 and 21 to 24 of gestational weeks. In one more research done by Dehghani-Firouzabadi uterine artery Doppler ultrasonography was conducted at fourteen to sixteen weeks of pregnancy (Caradeux et al., 2019; Seyam et al., 2002) and in our study ultrasonography was conducted between eighteen to thirty weeks than blood pressure and proteinuria checked to assess preeclampsia. Correspondingly, Anastasaks et al., (2008) study incidence of preeclampsia from twenty three to twenty five weeks of gestation and they performed intra vaginal uterine artery doppler ultrasound technique rather than trans abdominal method but, a fabricated on the follow-up examination of 162 pregnant ladies of the our study, $34 \%$ pregnant females were diagnosed with severe and non-severe hypertension, but no sign of gestational hypertension was observed in the other $66 \%$ of pregnant females. In relations of devising proteinuria, $33.3 \%$ pregnant females diagnosed by urine examination, correspondingly and $66.7 \%$ pregnant females, and urine samples were free from protein content was seen during pregnancy and this was made a relationship with preeclampsia. Turk et al., (2019) done a research of this topic and he evaluate that ten pregnant females of second or third trimester of pregnancy from the studied population diagnosed with PE from all of these two diagnosed from severe and eight pregnant females diagnosed with mild preeclampsia, correspondingly (Berkely et al., 2012; Azhar et al., 2020). For the prevention of high risk pregnancy related complications which as intrauterine growth restriction, intrauterine fetal deaths and also PE ,uterine artery doppler ultrasonography which is performed at 18 and 22 weeks of gestation might be useful as an appropriate method for diagnosis (Janwantanakul et al., 2008).

\section{Conclusion}

In this research we concluded that, preeclampsia and intrauterine growth restriction have relatively low incidence. From the results of our research, we have seen notching whatever on right, left or bilateral and pulsatility index are these diagnostic parameters to evaluate these complications before getting worse and uterine artery doppler ultrasound should be perform in every obstetric visit during pregnancy. Although the results vary according to risk factors of different pregnant females but in our results, we clearly found that there uterine artery Doppler predict pre eclampsia and IUGR in those women who had shown notches in their USG and after thirty weeks several tests and $\mathrm{BP}$ reading told us that uterine artery Doppler was good predictive measure, we also seen abnormal uterine artery waveforms are a better predictor of pre-eclampsia than of intrauterine growth restriction. We also concluded that pulsatility index, had also more than normal values in those pregnant females who has notches and those pregnant females, their ultrasound shows no notches ,their PI values are normal,so we can coorelate this variable that both have significant values. In future research should also concentrate on combining uterine artery Doppler ultrasonography

[Citation: Rashid M.N., Kari, M., Rashid, R., Rana, M.A., Amjad, A., Hafeez M.M. (2020). Uterine artery doppler indices as predictive measures for the pre-eclampsia and intrauterine growth restriction. Biol. Clin. Sci. Res. J., 2020: 23 doi: https://doi.org/10.54112/bcsrj.v2020i1.23] 
with different tests like proteinuria because these factors also correlates with assessing complications.

\section{Recommendation}

Routine BP monitoring should be done at primary health center and should be referred to tertiary center early if any intervention is required.

Administration of low dose aspirin increased calcium intake, antioxidant and nitric oxide usage can be instituted to prevent or arrest the progress of the disease and improve maternal and neonatal outcome.

\section{Acknowledgments}

I am thankful to Almighty Allah, the most beneficent and the most merciful and the Holy Prophet (P.B.U.H) for blessings upon me and giving me the courage and wisdom to complete this research successfully. I am very much indebted to my supervisor whose content supervision and instructions made me expeditious in my achievements. I also wish to say big thank to biostatistician for his guidance and help in every step of research work and all the teachers at radiology department UOL for their cooperation and for making me a better person throughout my degree. I would like to thank from bottom of my heart to Head of Department) for having faith in me and provides me an opportunity to study under his supervision and inspired and to believe in myself.

\section{Conflict of interest}

The authors declare absence of any conflict of interest.

\section{References}

Albu, A.R., Anca, A.F., Horhoianu, V.V., Horhoianu, I.A. (2014). Predictive factors for intrauterine growth restriction. Journal of Medicine and Life. 7(2): 165 .

Anastasakis, E., Paraskevas, K.I., Papantoniou, N., Daskalakis, G., Mesogitis, S., Mikhailidis, D.P., Antsaklis, A. (2008). Association between abnormal uterine artery Doppler flow velocimetry, risk of preeclampsia, and indices of arterial structure and function: a pilot study. Angiology. 59(4):493-9.

Azhar S, Huma Ze, Mahmood N, Azhar M, Hafeez MM, Azhar M, Malik A. (2020). comparison of predictive accuracy of transcerebellar diameter to abdominal circumference ratio (TCD/AC) versus head circumference to abdominal circumference ratio (hc/ac) in intrauterine growth restriction on ultrasonography. Inter. J. Biol. Pharm. Allied Sci.9; 4: 114-.123.

Berkley, E., Chauhan, S.P., Abuhamad, A, (2012). Society for Maternal-Fetal Medicine Publications Committee. Doppler assessment of the fetus with intrauterine growth
restriction.American journal of obstetrics and gynecology. 206(4):300-8.

Caradeux, J., Martinez-Portilla, R.J., Peguero, A., Sotiriadis, A., Figueras, F. (2019). Diagnostic Performance of Third Trimester Ultrasound for the Prediction of Late-Onset Fetal Growth Restriction: A Systematic Review and MetaAnalysis. American Journal of Obstetrics and Gynecology. 8.

Ciobanu, A., Rouvali, A., Syngelaki, A., Akolekar, R., Nicolaides, KH. (2019). Prediction of small for gestational age neonates: screening by maternal factors, fetal biometry, and biomarkers at 35-37 weeks se gestation. American Journal of Obstetrics and Gynecology. 220(5):486-e1.

Cnossen, J.S., Morris, R.K., Terriet, G., Mol, B.W., van der Post, J.A., Coomarasamy, A., Zwinderman, A.H., Robson, S.C., Bindels, P.J., Kleijnen, J., Khan, K.S. (2008). Use of uterine artery Doppler ultrasonography to predict preeclampsia and intrauterine growth restriction: a systematic review and bivariable meta-analysis. Canadian Medical Association Journal. 178(6):701-11.

Damodaram, M., Story, L, .Eixarch, E., Patel, A, McGuinness A, Allsop J, Wyatt-Ashmead, J., Kumar, S., Rutherford, M. (2010). Placental MRI in intrauterine fetal growth restriction. Placenta. 31(6):491-8.

Finn-Sell, S.L., Cottrell, E.C., Greenwood, S.L., Dilworth, M.R., Cowley, E.J., Sibley, C.P., Wareing, M. (2018). Pomegranate Juice Supplementation Alters Utero-placental Vascular Function and Fetal Growth in the eNOS-/-Mouse Model of Fetal Growth Restriction. Frontiers in Physiology. 9:1145.

Harman, C.R., Baschat, A.A. (2003). Comprehensive assessment of fetal wellbeing: which Doppler tests should be performed? Current Opinion in Obstetrics and Gynecology. 15(2):147-57.

Janwantanakul, P., Pensri, P., Jiamjarasrangsri, V., and Sinsongsook, T. (2008). Prevalence of selfreported musculoskeletal symptoms among office workers. Occupational Medicine 58, 436438.

Litwińska, E., Litwińska, M., Oszukowski, P., Szaflik, K., Kaczmarek, P. (2017). Combined screening for early and late pre-eclampsia and intrauterine growth restriction by maternal history, uterine artery Doppler, mean arterial pressure and biochemical markers. Advances in Clinical and Experimental Medicine. 26(3):43948.

MacDonald, T.M., McCarthy, E.A., Walker SP. (2015). Shining light in dark corners: Diagnosis and management of late-onset fetal growth

[Citation: Rashid M.N., Kari, M., Rashid, R., Rana, M.A., Amjad, A., Hafeez M.M. (2020). Uterine artery doppler indices as predictive measures for the pre-eclampsia and intrauterine growth restriction. Biol. Clin. Sci. Res. J., 2020: 23 doi: https://doi.org/10.54112/bcsrj.v2020i1.23] 
restriction. Australian and New Zealand Journal of Obstetrics and G4naecology. 55(1):3-10.

Malik A, Hafeez MM, Mansoor G, Alam R, Waqar S, Shafique H, Zahid A, Parveen G, Razzaq A, Ali Q. (2018). Interrelationship of circulating biohemical variables of medical importance and their role in the pathogenis of prostate cancer. Inter. J. Biol. Pharm. Allied Sci.7; 7: 1291-1304.

Malik A, Khan Mi, Hafeez Z, Zubair A, Hafeez MM, Chaudhary HRZ, Nazar W, Waquar S. (2020). Role of vitamin $d$ and oxidative stress markers in the development and progression of type 2 diabetes mellitus. Inter. J. Biol. Pharm. Allied Sci.9; 4: 613-6.26.

Pialis, A., Souka, P., Antsaklis, P. et al. (2007). Screening for pre-eclampsia and fetal growth restriction by uterine artery doppler and PAPP-A at 11-14 weeks gestation. Ultrasound Obstet Gynecol. 29: 135-140.

Seyam, Y.S., Al-Mahmeid, M.S., Al-Tamimi, H.K. (2002). Umbilical artery Doppler flow velocimetry in intrauterine growth restriction and its relation to perinatal outcome. International Journal of Gynecology \& Obstetrics. 77(2):131-7.

Turk, E.A., Stout, J.N., Ha, C., Luo, J., Gagoski, B., Yetisir, F., Golland, P., Wald, L.L., Adalsteinsson, E., Robinson, J.N., Roberts, D.J. (2019). Placental MRI: Developing Accurate Quantitative Measures of Oxygenation. Topics in Magnetic Resonance Imaging, 28(5):285-97.

Yamaleyeva, L,M., Brosnihan, K.B., Smith, L.M., Sun, Y. (2018). Preclinical Ultrasound-Guided Photoacoustic Imaging of the Placenta in Normal and Pathologic Pregnancy.Molecular imaging. 16;17:1-5. made. The images or other third party material in this article are included in the article's Creative Commons licence, unless indicated otherwise in a credit line to the material. If material is not included in the article's Creative Commons licence and your intended use is not permitted by statutory regulation or exceeds the permitted use, you will need to obtain permission directly from the copyright holder. To view a copy of this licence, visit http://creativecommons.org/licen ses/by/4.0/.

(C) The Author(s) 2021

\section{(c) (7) 8}

Open Access This article is licensed under a Creative Commons Attribution 4.0 International License, which permits use, sharing, adaptation, distribution and reproduction in any medium or format, as long as you give appropriate credit to the original author(s) and the source, provide a link to the Creative Commons licence, and indicate if changes were
[Citation: Rashid M.N., Kari, M., Rashid, R., Rana, M.A., Amjad, A., Hafeez M.M. (2020). Uterine artery doppler indices as predictive measures for the pre-eclampsia and intrauterine growth restriction. Biol. Clin. Sci. Res. J., 2020: 23 doi: https://doi.org/10.54112/bcsrj.v2020i1.23] 